\title{
McArdle Disease: A Unique Study Model in Sports Medicine
}

\author{
Alfredo Santalla $\cdot$ Gisela Nogales-Gadea $\cdot$ \\ Niels Ørtenblad • Astrid Brull • Noemi de Luna • \\ Tomàs Pinós $\cdot$ Alejandro Lucia
}

Published online: 16 July 2014

(c) Springer International Publishing Switzerland 2014

\begin{abstract}
McArdle disease is arguably the paradigm of exercise intolerance in humans. This disorder is caused by inherited deficiency of myophosphorylase, the enzyme isoform that initiates glycogen breakdown in skeletal muscles. Because patients are unable to obtain energy from their muscle glycogen stores, this disease provides an interesting model of study for exercise physiologists, allowing insight to be gained into the understanding of glycogen-dependent muscle functions. Of special interest in the field of muscle physiology and sports medicine are also some specific (if not unique) characteristics of this disorder, such as the so-called 'second wind' phenomenon, the frequent exercise-induced rhabdomyolysis and myoglobinuria episodes suffered by
\end{abstract}

A. Santalla, G. Nogales-Gadea, T. Pinós, and A. Lucia contributed equally to this article.

\section{A. Santalla}

Universidad Pablo Olavide, Sevilla, Spain

A. Santalla

Instituto de Investigación Hospital 12 de Octubre $(i+12)$,

Madrid, Spain

G. Nogales-Gadea

Neuromuscular Diseases Unit, Neurology Department, Hospital de la Santa Creu i Sant Pau,

Universitat Autónoma de Barcelona, Barcelona, Spain

G. Nogales-Gadea

Division of Neuroscience, Faculty of Health, Medicine, and Life Sciences, School for Mental Health and Neuroscience,

Maastricht University, Maastricht, The Netherlands

\section{N. Ørtenblad}

Department of Sports Science and Clinical Biomechanics, SDU Muscle Research Cluster (SMRC), University of Southern Denmark, Odense, Denmark patients (with muscle damage also occurring under basal conditions), or the early appearance of fatigue and contractures, among others. In this article we review the main pathophysiological features of this disorder leading to exercise intolerance as well as the currently available therapeutic possibilities. Patients have been traditionally advised by clinicians to refrain from exercise, yet sports medicine and careful exercise prescription are their best allies at present because no effective enzyme replacement therapy is expected to be available in the near future. As of today, although unable to restore myophosphorylase deficiency, the 'simple' use of exercise as therapy seems probably more promising and practical for patients than more 'complex' medical approaches.

N. Ørtenblad

Swedish Winter Sports Research Centre, Mid Sweden

University, Östersund, Sweden

A. Brull · N. de Luna · T. Pinós $(\bowtie)$

Departament de Patologia Mitocondrial i Neuromuscular, Hospital Universitari Vall d'Hebron, Institut de Recerca (VHIR), Universitat Autónoma de Barcelona, Pg. Vall d'Hebron 119, 08035 Barcelona, Spain

e-mail: tomas.pinos@vhir.org

A. Brull · N. de Luna - T. Pinós

Centre for Biomedical Network Research on Rare Diseases (CIBERER), Instituto de Salud Carlos III, Madrid, Spain

\section{A. Lucia}

Universidad Europea e Instituto de Investigación Hospital 12 de Octubre $(i+12)$, Madrid, Spain

e-mail: alejandro.lucia@uem.es 


\section{Key Points}

Glycogen is an important fuel during exercise, and low glycogen availability (as occurs in McArdle disease) impairs muscle function and basic cellular events

McArdle disease is the paradigm of exercise intolerance and is an excellent model for studying the physiology of muscle fatigue

Although frequently overlooked in clinical settings, exercise interventions are among the best therapeutic options for this and other debilitating diseases

\section{Introduction}

Glycogenosis type $\mathrm{V}$ [glycogen storage disease type $\mathrm{V}$ (GSD V), McArdle disease or myophosphorylase deficiency; OMIM ${ }^{\circledR}$ database number 232600] is a disorder of skeletal muscle carbohydrate metabolism first described by Brian McArdle in 1951 [1]. It is one of the most frequent genetic myopathies, e.g. a prevalence of $\sim 1 / 167,000$ in Spain as of January 2011, with both sexes equally affected [2]. This disease is inherited in an autosomal recessive manner and produced by pathogenic mutations in both copies of the gene [phosphorylase, glycogen, muscle $(P Y G M)]$ encoding the muscle isoform of glycogen phosphorylase, myophosphorylase [2]. Based on our count of reported mutations, $\sim 150$ mutations have been described in Caucasian patients, with p.R50X being clearly the most prevalent variant, e.g. reported allele frequencies of $43 \%$ (Italy) [3], $55 \%$ (Spain) [2] or $77 \%$ (UK) [4].

Because myophosphorylase catalyzes and regulates the breakdown of glycogen into glucose-1-phosphate in muscle fibers (by removing $\alpha-1,4$ glucosyl units from the outer glycogen branches) [5], patients are unable to obtain energy from their muscle glycogen stores [6]. Of note, glycolysis is blocked upstream, and thus the muscle fibers of McArdle disease patients can take up glucose from the blood and convert it into glucose-6-phosphate, which then enters the downstream steps of glycolysis [6] (Fig. 1). Muscle glycolysis is not, therefore, totally impaired in these patients, yet this disorder is arguably the paradigm of exercise intolerance in humans [7], thereby providing a quite unique model of study in the field of sports medicine [8].

Exercise intolerance (as described in the next section) is present in virtually all patients and often starts during childhood (e.g. in physical education classes). For example, $58 \%$ of patients reported that symptoms started in the

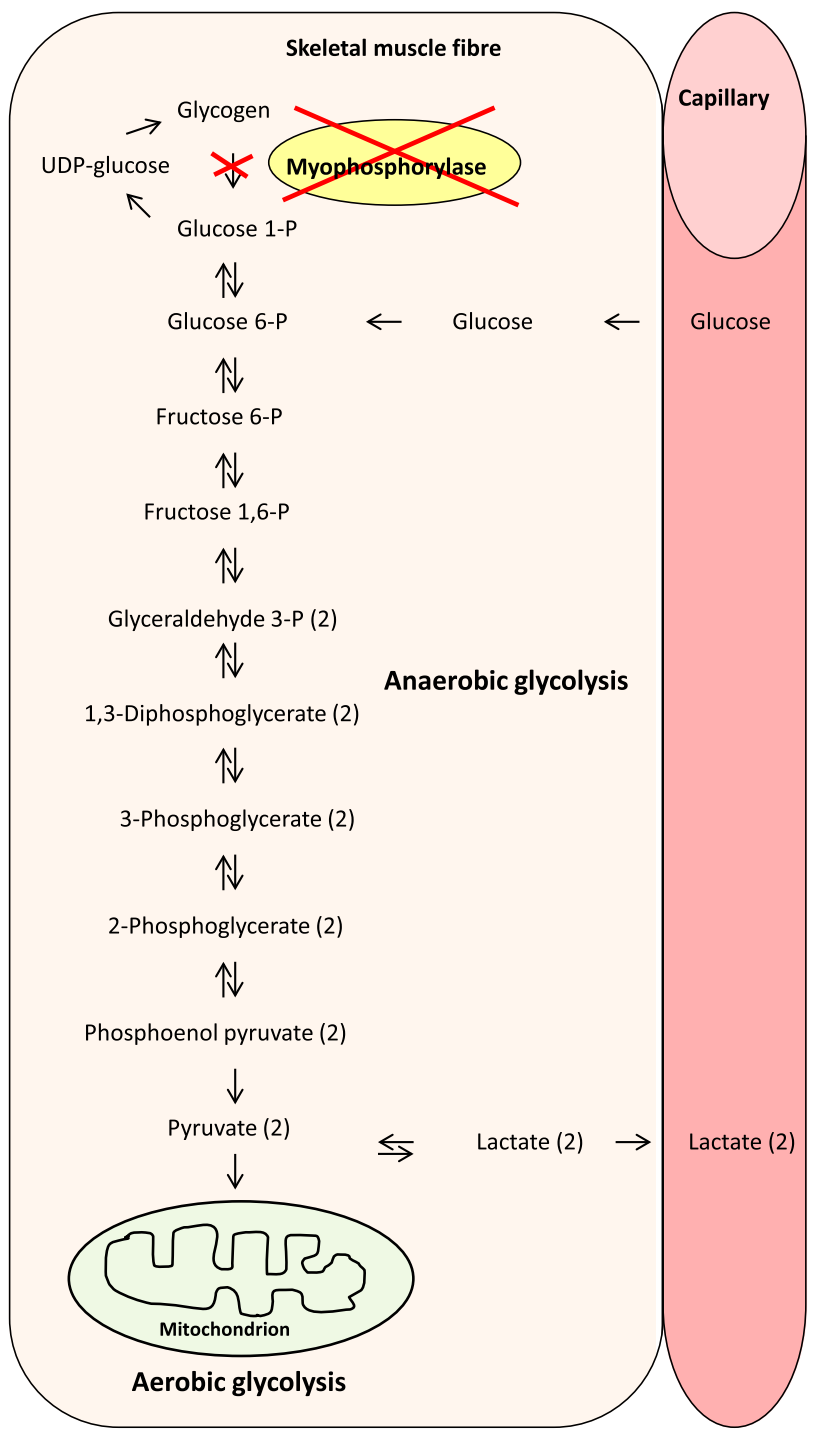

Fig. 1 Schematic representation of the metabolic blockade caused by McArdle disease. Deficiency of myophosphorylase (which catalyzes the first step of glycogen breakdown) results in patients' inability to obtain energy from muscle glycogen stores. However, because glycolysis is blocked upstream, the blood glucose that enters the muscle fibers can be converted into glucose-6-phosphate, which is metabolized in the downstream steps of glycolysis. $P$ phosphate, UDP uridine diphosphate. Arrows denote the direction of the chemical reaction

first decade of life, but others reported that they appeared later in life (i.e. $28 \%$ in the second decade and $14 \%$ in the third or fourth decade) [2]. The intensity of the stimuli causing intolerance also shows inter-individual variability; in some rare cases (fittest patients) symptoms are triggered only by sports participation, whereas most people show intolerance to almost all types of physical exercise [2], and $\sim 25 \%$ of patients also report functional limitations during 
daily life activities such as household tasks, personal care, lifting/carrying weights during shopping, or carrying children [2].

\section{Main Clinical Features of the Disease}

\subsection{Exercise Intolerance}

Exercise intolerance typically consists of acute crises of early fatigue and muscle stiffness and contractures, especially at the start of exercise, which usually disappear if exercise is stopped or intensity is reduced [9]. However, these episodes are sometimes accompanied by marked muscle damage or rhabdomyolysis, as reflected by the efflux of intramuscle proteins to the bloodstream, e.g. creatine kinase (CK) and myoglobin. Thus, high serum CK activity (typically $>1,000 \mathrm{U} / \mathrm{L}$ ) triggered by exercise is a common finding which can be accompanied by myoglobinuria, typically referred to as 'dark urine' $[2,10,11]$. In fact, $50 \%$ of patients report recurrent episodes of dark urine [2]. The main potential danger of exertional rhabdomyolysis is acute renal failure as well as hyperkalemia, with the former eventually leading to chronic renal failure, although reported cases of life-threatening situations are very scarce [2]. For these potential threats, patients have been traditionally advised by clinicians to refrain from exercise practice.

\subsection{The Second Wind}

A unique feature of the disease is the so-called 'second wind' phenomenon [12,13], which most patients refer to as the ability to resume dynamic, large-mass exercise (e.g. brisk walking) if they take a brief rest upon the appearance of premature fatigue early in exercise [6]. The second wind is easily detectable during a constant-load ( $\sim 40$ watts or $\geq 65 \%$ age-predicted maximum heart rate) cycle-ergometer test, with all adult patients showing a decrease in early exertional tachycardia (from $\sim 140-150$ to $\sim 120$ beats/ $\min$ ) after 7-8 min, and most reporting a decrease in local leg-muscle pain $[2,12]$. The first few minutes of exercise act as a warm-up (e.g. inducing muscle vasodilation), after which more circulating free-fatty acids as well as glucose are available to working muscle fibers that can oxidize these substrates, leading to attenuation of exercise intolerance [9]. In fact, Haller and Vissing [9] elegantly showed that the 'second wind' phenomenon is abolished by glucose infusion or sucrose ingestion before exercise [14].

\subsection{Fixed Muscle Weakness}

Around $25 \%$ of patients also develop fixed weakness and wasting (affecting more proximal than distal muscles), which is aggravated with aging $[2,15]$. This phenomenon has been attributed to the cumulative effect of repeated episodes of rhabdomyolysis [16], but this hypothesis remains to be proven.

\section{Pathophysiology of Exercise Intolerance in McArdle Patients}

\subsection{Role of Glycogen in Human Muscle Function}

Endogenous muscle glycogen represents a primary fuel source during exercise, and the relationship between glycogen and endurance exercise capacity is a fundamental concept in exercise physiology [17-19]. For more than 50 years it has been understood that alterations in preexercise muscle glycogen reserves by dietary or exercise manipulations, affect fatigue resistance. These observations have served to establish a close relationship between muscle glycogen and endurance and it is now generally recognized that adequate reserves of muscle carbohydrates are indispensable for sustained performance during moderate to heavy exercise. Thus, previous studies $[20,21]$ demonstrated a strong correlation between muscle glycogen content and endurance capacity during prolonged cycling exercise and an inability to continue such exercise when the glycogen stores were depleted [21]. As a consequence, high pre-exercise muscle and liver glycogen concentrations are believed to be essential for optimal performance [22]. While muscle fatigue is a multifactorial phenomenon depending on exercise mode, intensity and duration, the now well-established relationship between muscle glycogen content and fatigue resistance is not only evident during prolonged $(>1 \mathrm{~h})$ exercise, but also established during high-intensity intermittent exercise [18, 23, 24]. However, the link between glycogen depletion and the development of fatigue, as well as the precise mechanism whereby muscle glycogen affects the series of events that ultimately result in fatigue, is not yet fully understood.

Studies on both rodent single fibers and humans have pointed to a modulating role of glycogen availability on sarcoplasmic reticulum (SR) $\mathrm{Ca}^{2+}$ handling [25-28]. Thus, tetanic $\mathrm{Ca}^{2+}$ levels in the muscle fiber and the SR $\mathrm{Ca}^{2+}$ release rate are markedly reduced when muscle glycogen levels are low, indicating a relationship between $\mathrm{Ca}^{2+}$ and muscle glycogen. Furthermore, it has been revealed that the $\mathrm{Na}^{+}-\mathrm{K}^{+}$adenosine triphosphate (ATP)-ase preferentially uses glycolytic-derived ATP, indicative of a role of glycogen in maintaining muscle excitability during repeated depolarizations [29, 30].

Although glycogen has been traditionally interpreted as if it is uniformly distributed in the fiber, providing an average concentration of this cell, electron microscopy images have revealed that glycogen is found as discrete particles in 
distinct pools within the fibers [31-34]. Furthermore, each glycogen granule has its own metabolic machinery with glycolytic enzymes and regulating proteins $[35,36]$. Three distinct intracellular pools of glycogen have been identified: (i) subsarcolemmal glycogen, just beneath the sarcolemma; (ii) intermyofibrillar glycogen, located between the myofibrils, mainly at the level of the I-band close to the mitochondria and the SR; and (iii) intramyofibrillar glycogen, within the myofibrils. The major glycogen pool is the intermyofibrillar, constituting $\sim 75 \%$ of the total glycogen store, whereas intramyofibrillar and subsarcolemmal glycogen accounts for 5-15\% each. However, the relative distribution of glycogen in these pools is dependent on a variety of factors, such as fiber type, training status, immobilization, acute exercise and species (rodent, man) [37]. The three spatially distinct pools of glycogen within skeletal muscle fibers have been shown to influence different events in the excitation of the muscle fiber, and independently affect contractility and fatigability (for a review see Ortenblad et al. [28]). Thus, the subcellular localization of glycogen has to be taken into consideration to fully understand the role and regulation of glycogen metabolism on skeletal muscle function. The specific pool of intramyofibrillar glycogen is the smallest pool and, in relative terms, the main utilized glycogen depot during exercise. Furthermore, the glycogen content in this depot, and not subsarcolemmal or intermyofibrillar glycogen, is correlated with the $\mathrm{Ca}^{2+}$ release rate in SR vesicles [27], as well as with the amount of tetanic intracellular free $\left[\mathrm{Ca}^{2+}\right]$ during fatiguing contractions [38] and the endurance capacity of mechanically skinned fibers [39]. These observations suggest a specific importance of intramyofibrillar glycogen in muscle function and that exhaustion of this glycogen depot may explain the association of glycogen with muscle fatigue [40]. In support of this, it has been demonstrated that glycogen, associated proteins and glycolytic intermediates, interact with the SR membrane [36, 40, 41] and affect the $\mathrm{Ca}^{2+}$ release properties of the SR [42]. Of note, a muscle biopsy hallmark of McArdle disease is the chronically elevated glycogen store deposits, both at the high subsarcolemmal and intermyofibrillar level [7, 43, 44], but to our knowledge no information is available on the intramyofibrillar glycogen deposits in these patients.

Because patients are unable to use their muscle glycogen, McArdle disease, especially the recently generated transgenic mouse model (as discussed below, see Sect. 4), provides a unique model to understand the function of glycogen deposits in the development of fatigue.

\subsection{Main Pathophysiological Features in McArdle Patients}

Patients' exercise intolerance is especially evident during exercise tasks involving (aerobic/anaerobic) glycolysis for muscle ATP production [7]. Thus, 'muscle crises' are typically triggered by acute, intense, large-mass exercise tasks (e.g. sprinting to catch a bus), especially by 'static' (or isometric) contractions relying on smaller muscle groups as well as on anaerobic metabolism, e.g. lifting/ carrying weights or isometric exercises such as handgrip $[2,6,7]$. During the latter, high mechanical demands are imposed on relatively low muscle mass, and the sustained muscular contraction increases the pressure inside the muscle, causing the supply of oxygenated blood to be transiently cut off or at least considerably decreased $[2,7]$. This can be aggravated by the fact that excessive glycogen storage ( $\sim 2-3$ times higher than in normal people) may mechanically disrupt the contractile apparatus [6].

Dynamic exercises involving higher muscle mass and lesser mechanical loads while relying mostly on aerobic pathways (stair climbing, running, brisk walking) can also trigger acute exercise intolerance in McArdle disease patients. Indeed, their muscle oxidative capacity is usually impaired; owing to blocked glycogenolysis, their muscles' ability to produce pyruvate, a molecule that plays an anaplerotic role in the Krebs cycle, is severely reduced [7]. Impaired muscle oxidative capacity is reflected in phosphorus magnetic resonance spectroscopy $\left({ }^{31} \mathrm{P}-\mathrm{MRS}\right)$ by (i) significantly greater phosphocreatine consumption and lower ATP concentrations compared with healthy controls after submaximal isometric calf contractions [6], or (ii) higher intracellular adenosine diphosphate (ADP) concentrations at the beginning of recovery from ischemic exercise [45]. Owing to the marked decrease in skeletal muscle phosphorylation capacity (decreased [ATP]/[ADP][inorganic phosphate, $\mathrm{Pi}]$ ratio), $\mathrm{Pi}$ and probably also ADP accumulates in patients' muscles, thereby potentially inhibiting (i) the myofibrillar ATPase, (ii) the SR $\mathrm{Ca}^{2+}$ ATPase (SERCA) pump, and (iii) the $\mathrm{Na}^{+}-\mathrm{K}^{+}$ATPase (or 'pump') reactions, possibly leading to decreased contractility and premature fatigue [46-48].

\subsection{Hyperkinetic Cardiorespiratory Response to Exertion}

Patients often show an abnormally high cardiac output and heart rate at a given workload during dynamic exercise [49]. This 'hyperkinetic' circulation could be mediated by the local effects of $\mathrm{K}^{+}, \mathrm{Pi}$, or adenosine, or a combination of these substances, released excessively from working skeletal muscles on metabolically sensitive skeletal muscle afferents and vascular smooth muscle [49]. Although the abnormal cardiovascular response to exercise in McArdle disease patients could also indicate an excessive increase in sympathetic nervous system activity, previous research has shown that these patients have normal muscle sympathetic nerve responses to exertion, at least for static (handgrip) 
exercise [50]. The abnormal cardiovascular response to dynamic exercise in these patients could also be due, at least in part, to an altered central motor pattern, which may manifest as exaggerated motor unit recruitment for a given workload.

\subsection{Low Muscle Contractility}

Using surface electromyography (EMG), which permits measurement of muscle fiber recruitment, Rae et al. recently showed that, for the same relative level of EMG activity, and thus at the same relative degree of recruitment, the muscles of McArdle disease were able to produce only about one-third of the power produced by age- and sex-matched healthy controls during a ramp cycle-ergometer test [51]. The mean \pm SD peak power output at the end of the test was only $67 \pm 21 \mathrm{~W}$ (range 27-107) in 37 adult McArdle disease patients of both sexes versus $214 \pm 56 \mathrm{~W}$ (range 92-313) in their controls. On the other hand, the McArdle disease patients showed higher levels of EMG activity at the same relative workload during a submaximal constant-load cycle-ergometer test. Thus, it was hypothesized that the low capacity for producing peak muscle power as well as the high muscle mass recruitment for a given power in McArdle disease patients might reflect impaired muscle contractility.

\subsection{Downregulation of Sarcoplasmic Reticulum Calcium ATPase 1 (SERCA1) Leading to Impaired Muscle Relaxation}

Besides the abovementioned hypothesis of altered contractility, it could also be that muscle relaxation is delayed in patients with McArdle disease so that the muscle cannot sustain a high cadence of contraction and experiences early fatigue during exercise. Indeed, human muscle fatigue is usually accompanied by a slowing of relaxation [52] and high rates of glycolytic ATP production, since up to $80 \%$ of the ATP consumed during contraction is required for optimum muscle relaxation, i.e. for adequate removal of $\mathrm{Ca}^{2+}$ from the sarcoplasm back into the SR [52, 53]. Nogales-Gadea et al. [54] recently found evidence of downregulation of SR calcium ATPase 1 (SERCA1) in the muscle of McArdle disease patients compared with healthy controls. Partial reductions in the activity or total amount of SERCA1 due to SERCA1 gene mutations cause a disorder known as Brody myopathy [55], a rare skeletal muscle condition that shares some common clinical features with McArdle disease, i.e. patients experience progressive muscle stiffness during exercise, leading to contractures [56]. Lack of SERCA1 also causes neonatal death in mice [57]. SERCA1 is a $\mathrm{Ca}^{2+}$ transporter ATPase located in the SR of fast-twitch, type II fibers that is essential for normal development of contraction-relaxation cycles in these fibers, which are mainly glycogenolytic and therefore more sensitive to myophosphorylase deficiency. Thus, SERCA1 reduction may preferentially affect those exercise tasks involving type II muscle fibers and that typically cause more severe intolerance in McArdle disease patients, such as isometric exercise or lifting weights. Additionally, concentrations of $\mathrm{Ca}^{2+}$, ATP, ADP or Pi [58] can modify the phosphorylation rate of SERCA1, and some of these factors are reported to be deregulated in McArdle disease, notably increased [ADP] and [Pi], as mentioned above (Sect. 3.2).

Of note, the fact that deficient glycogen-dependent ATP supply can result in downregulation of $\mathrm{Na}^{+}-\mathrm{K}^{+}$pumps in the skeletal muscle fibers of patients with McArdle disease might lead to contractures (sometimes referred to as 'cramps' in the sports setting) owing to loss of membrane excitability and exercise-induced hyperkalemia [46]. In addition, contrary to 'traditional beliefs', lactic acidosis does not necessarily impair muscle performance and could in fact protect against muscle fatigue (see Cairns [59] for a review), e.g. by virtue of its effect of maintaining muscle membrane excitability by decreasing chloride permeability [60] or by counteracting the depressing effects that the efflux of $\mathrm{K}^{+}$from working fibers has on membrane excitability [61] and on force of contraction [62].

\subsection{Low Gross Mechanical Efficiency}

It seems that the oxygen consumed by the muscles of McArdle disease patients is not converted into the expected power production. This is supported by the higher slope of the oxygen uptake $\left(\mathrm{VO}_{2}\right)$ to watts relationship during ramp cycle-ergometer tests [51, 63] and the very low gross mechanical efficiency values of these patients during constant, submaximal workload cycle-ergometer tests, where their muscles are only able to convert $13 \%$ of the total oxygen they consume into mechanical work [64]; this is in contrast with the mean gross mechanical efficiency of the age- and sex-matched controls group (19\%), as well as with the normal 18-22\% range expected in non-athletic, healthy people [65]. Although more research is needed, the main reason for this phenomenon is likely the abovementioned excessive muscle recruitment (Sect. 3.4), with other potential mechanisms (which in turn can also impair contractility) being low capacity for $\mathrm{Ca}^{2+}$ removal from the $\mathrm{SR}$, or increased dependence on fat metabolism owing to the inherited block in muscle glycogen metabolism [51]. With regards to the latter hypothesis, carbohydrates are indeed more efficient fuels than fat in terms of generating ATP per mole of oxygen [66]. 
3.7 The Pathophysiology of Exertional Rhabdomyolysis and Basal 'Hyper-CK-Emia': Muscle Oxidative Stress Involved?

As noted above (Sect. 2.1), exercise-induced rhabdomyolysis is the main medical problem of McArdle disease, mainly due to its potential to cause renal failure [2, 4, 67-71]. The causes for exertional rhabdomyolysis to occur frequently in these patients remain to be clearly elucidated, although the mechanical stress imposed by high muscle glycogen stores [6] and particularly the documented downregulation of $\mathrm{Na}^{+}-\mathrm{K}^{+}$pumps in patients' muscles [46] (with these pumps being responsible for maintaining cellular volume and integrity), are candidates to contribute to structural muscle fiber fragility and membrane disruption, leading to the efflux of intracytoplasmic proteins such as $\mathrm{CK}$ to the bloodstream. An additional proposed factor is increased oxidative stress.

Owing to reduced glycolytic flux in the working muscles of these patients, there is frequently a mismatch between ATP consumption and production. Thus, two ADP molecules can combine to regenerate ATP by the myokinase (or adenylate kinase 1) pathway in an attempt to keep up with ATP demand. In this reaction, adenosine monophosphate (AMP) is produced and removed by AMP deaminase 1 , resulting in the production of $\mathrm{NH}_{3}{ }^{+}$and inosine monophosphate (IMP), the latter being metabolized to inosine and then to hypoxanthine, xanthine, and uric acid via xanthine oxidase, which generates reactive oxygen species (ROS). There is indeed evidence of increased levels of muscle ADP [72] and plasma $\mathrm{NH}_{3}{ }^{+}$ and hypoxanthine during exercise in McArdle disease patients compared with non-patients [72, 73], suggesting high oxidative stress in their skeletal muscles. However, another characteristic of the disease is a high serum level of $\mathrm{CK}$ activity, even under basal conditions, i.e. in the absence of heavy exercise in the previous few hours or days, e.g. $>1,000 \mathrm{U} / \mathrm{L}$ in $\sim 80 \%$ of all Spanish patients [2]. The reason for this striking phenomenon remains to be elucidated, although oxidative damage could also be involved. Indeed, compared with healthy age- and physical activity-matched controls, McArdle disease patients have higher basal muscle levels of a marker of oxidative stress, muscle protein carbonyls and 4-hydroxynonenal (4$\mathrm{HNE}$ ), together with a compensatory upregulation of the nuclear factor erythroid 2-related factor 2 (Nrf2)-mediated antioxidant response [74]. Also, the possibly elevated levels of $\mathrm{Ca}^{2+}$ in the sarcoplasm (owing to downregulated SERCA1, see Sect. 3.5) might activate proteases, phospholipases and other catabolic enzymes, causing not only structural damage but also initiating muscle fatigue and cramping [75].

\subsection{Low-Grade Systemic Inflammation}

When muscle injury occurs, e.g. typically after an exercise task with a strong eccentric component, the process of tissue repair is initiated with the induction of an acutephase response and upregulation of a group of messenger molecules collectively known as cytokines [76]. Cytokines are released at the site of inflammation, initiating a systemic inflammatory response $[77,78]$. On the other hand, several chronic diseases (e.g. cardiovascular disease, type II diabetes), as well as physical inactivity, are associated with a chronic state of systemic low-level inflammation, i.e. increases in neutrophil and natural killer cell counts as well as in circulating levels of cytokines, such as tumor necrosis factor (TNF)- $\alpha$ [79]. In contrast, the benefits of regular physical exercise are partly mediated by its antiinflammatory effects; working muscles release bioactive molecules (myokines) to the bloodstream with a potential beneficial health effect at the systemic level or in other tissues, such as interleukin (IL)-6, which promotes an antiinflammatory milieu [80].

Possibly because of the continuous state of muscle damage experienced by patients with McArdle disease, basal blood levels of neutrophil count and several cytokines [TNF- $\alpha$, IL-1 receptor antagonist (IL-1ra), IL-10, IL12 and IL-17] were shown to be significantly higher in patients than in controls [81]. In turn, non-eccentric (cycling) exercise induced a similar response in McArdle patients and healthy controls, i.e. increased serum levels of the anti-inflammatory myokine IL-6. It was thus suggested that McArdle disease is associated with low-level systemic inflammation, strengthening the rationale for prescribing carefully supervised exercise training in these patients.

\subsection{Downregulation of Glycogen Synthase:}

A Beneficial (Protective) Mechanism?

Skeletal muscle is the major site of insulin-stimulated glucose uptake, and most of this glucose is stored as glycogen through glycogen synthase (GS), which has the opposite function of myophosphorylase but shares regulatory mechanisms with the latter enzyme, i.e. covalent modification, allosteric activation, and enzymatic translocation [82]. Evidence of deregulation in the GS pathway has been reported in McArdle disease patients [54, 83-85], who have decreased insulin action in skeletal muscle compared with healthy controls after a hyperinsulinemic clamp, resulting in lower glucose use and lower GS activity [83]. Nielsen et al. [83] elegantly showed that a group of six McArdle disease patients had normal fasting plasma glucose and plasma insulin levels, although four of them were categorized as having impaired glucose tolerance after an oral glucose tolerance test. The authors 
hypothesized that the decreased glucose uptake in muscle fibers might be compensated with other mechanisms augmenting glucose uptake in extramuscular tissue, such as the liver. Studies in larger series of patients do not show a higher incidence of diabetes in McArdle disease patients despite the decreased insulin action in their skeletal muscles. For instance, the prevalence of diabetes in the Spanish registry of McArdle disease patients (10\%) [2] is similar to that reported in Spanish adults, i.e. 10-15\% [86].

McArdle disease patients have low GS activity during exercise [84] as well as higher and lower levels of inactive and active enzyme forms, respectively, than healthy controls $[54,85]$. The activity of GS is regulated by a complex, multisite phosphorylation mechanism comprising several protein kinases [87]. Furthermore, GS presents a phosphorylation-dependent intracellular distribution [88] with different phosphorylation sites associated with intramyofibrillar and the two other pools of subsarcolemmal and intermyofibrillar glycogen [33, 89]. Depletion of muscle glycogen during exercise activates GS [90], and this activation is greater when muscle glycogen is lower [91], resulting in a faster rate of glycogen resynthesis. The absence of glycogen degradation during exercise in patients with McArdle disease is associated with a slight decrease in GS activity [84] and the link between glycogen and GS may be mediated by protein phosphatase 1 , which is targeted to the glycogen molecule [92]. Thus, the high glycogen levels found in the muscle biopsies of these patients could be one of the contributors to GS inactivation [54], maybe playing a protective mechanism against an exaggerated, harmful accumulation of glycogen.

The current body of knowledge and postulated hypotheses on the pathophysiology of McArdle disease (explaining their exercise intolerance) is summarized in Fig. 2.

\subsection{Muscle Pathology}

A main finding in the muscle biopsies of McArdle disease patients is the accumulation of subsarcolemmal vacuoles that are periodic acid-Schiff (PAS) positive, due to glycogen aggregates, and the absence of staining for phosphorylase activity [5]. Some necrotic or regenerating fibers can be present. The regenerating fibers are positive for phosphorylase due to expression of the fetal isoenzyme (brain isoenzyme) in these fibers [93, 94]. Other findings have only been reported in a few studies, i.e. selective atrophy of type I fibers [95] and fiber grouping [44].

\subsection{More than Just a Skeletal Muscle Disease?}

McArdle disease is commonly accepted as a 'pure' myopathy, and only few studies have analyzed the potential implication of extramuscular tissues in the disease phenotype; however, myophosphorylase expression has also been reported in brain and heart tissue [96-98].

The human brain contains both brain and muscle isoforms of glycogen phosphorylase, with the latter representing $\sim 25 \%$ of the total amount of glycogen phosphorylase [96]. Thus, the total quantity of glycogen phosphorylase might be reduced in the brain of McArdle disease patients owing to their inherited myophosporylase deficiency. However, whether this hypothetical phenomenon affects the metabolism of patients' neurons remains to be elucidated. With regards to this, some cases of patients presenting with chronic fatigue-like symptoms, seizures, anxiety or depression have been reported $[4,99,100]$, and preliminary data suggest lower performance of McArdle patients in cognitive tests compared with healthy controls [101], which is in line with a published case report of impaired verbal learning, selective attention, and executive functions in a 55-year-old patient [102].

Like the brain, the heart expresses both muscle and brain isoforms of glycogen phosphorylase [96]. Therefore, the heart tissue of McArdle patients might also have diminished levels of total glycogen phosphorylase activity. Although cardiac involvement in McArdle disease is very rare, some cases of patients presenting with coronary artery disease [103], electrocardiogram changes [104], degenerative vascular disease [105] and obstructive hypertrophic cardiomiopathy have been reported [106]. However, more research is needed to clearly prove a cause:effect relationship between McArdle disease and the reported cardiac conditions.

\section{Recent Generation of a Promising Murine Model of McArdle Disease}

Two spontaneous animal models for McArdle disease have been identified in Charolais cattle [107] and Merino sheep [108], which, despite showing rhabdomyolysis, exercise intolerance, as well as lower force of contraction and greater fatigue in muscle contractility studies [109], have rendered a relatively limited amount of information on the pathophysiology of the disorder. This prompted our group to develop a genetically modified murine model of McArdle disease (knock-in mouse for the common PYGM p.R50X mutation) [110]. In contrast to available rodent models for other neuromuscular diseases, which do not show a human-like phenotype, our model presents with the main features of the patients' phenotype.

Knock-in mice homozygous for the common p.R50X human mutation show absence of myophosphorylase activity in muscle and subsequent blocked glycogenolysis, with massive glycogen accumulation in the gastrocnemius 


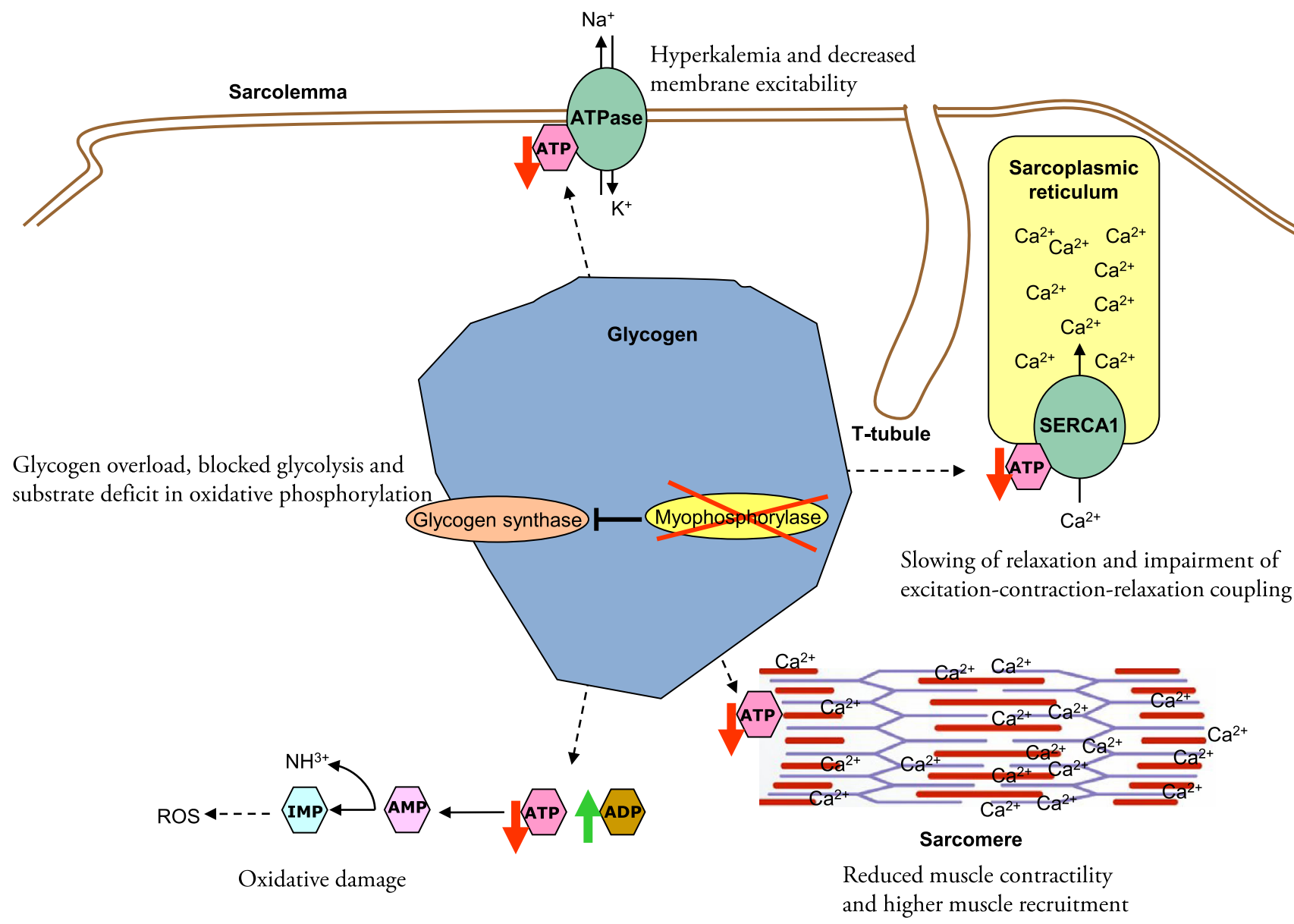

Fig. 2 The pathophysiology of exercise intolerance and muscle damage in McArdle disease. $A D P$ adenosine diphosphate, $A M P$ adenosine monophosphate, ATP adenosine triphosphate, IMP inosine

muscle, not only subsarcolemmal, as typically described in patients [15], but also intrasarcoplasmic. Interestingly, the glycogen accumulation was more pronounced in less oxidative (type II) fibers, which are more dependent on glycogen metabolism [110]. The knock-in mice also showed marked intolerance to isometric (wire grip) and intense dynamic exercise (treadmill running until exhaustion) [110]. They also had high basal 'hyper-CK-emia' and exercise-induced myoglobinuria. Thus, with the exception of the much higher glycogen stores compared with humans, this novel murine model mimics the human disease phenotype well and may represent a good tool for in-depth studies of (i) the pathophysiology of McArdle disease; (ii) the importance of glycogen deposits and its different localizations on muscle function (in a model where glycogen availability is absent); (iii) training adaptations at the muscle molecular level; and (iv) new therapeutic approaches for this and other neuromuscular diseases [because p.R50X is a nonsense mutation affecting only one tissue, muscle, whose function can be finely evaluated, our model monophosphate, $R O S$ reactive oxygen species, SERCA1 sarcoplasmic reticulum $\mathrm{Ca}^{2+}$ ATPase 1. Arrows with dashed lines denote inhibition

could also be used for exploring novel pharmacological approaches based on 'read through' strategies targeting premature termination codon (PTC) mutations; see Sect. 5.1.2].

\section{Treatment Options}

At present, there is no curative therapy for McArdle disease and no effective biomedical treatment is expected to be available in the foreseeable future to replace myophosphorylase deficiency in humans.

5.1 Treatments that have not yet Proven Efficient in Human Patients

\subsubsection{Nutritional Supplements/Drugs}

No significant beneficial effects have been reported in McArdle disease patients receiving branched chain amino 
acids [111], depot glucagon [112], dantrolene sodium [113], verapamil [114], vitamin B6 [115] (except in one recent case report [116]), or high-dose oral ribose [117]. More controversial are the results for creatine supplementation, although data are not promising either; low-dose supplementation $(60 \mathrm{mg} / \mathrm{kg} /$ day for 4 weeks $)$ attenuated muscle complaints in five of nine McArdle disease patients tested [118], but higher doses $(150 \mathrm{mg} / \mathrm{kg} / \mathrm{day})$ actually increased exercise-induced myalgia for unknown reasons [119].

\subsubsection{Stop Codon-Based Therapies}

Approximately one-third of all genetic inherited diseases are caused by PTC mutations [120]. This type of mutation leads to a cellular self-protective process known as 'nonsense-mediated messenger RNA decay' aiming at eliminating the majority of messenger RNA transcripts containing nonsense and frame-shift mutations [121]. The fact that several different compounds, such as aminoglycoside antibiotics [122], PTC124 [123], RTC13 [124] or amlexanox [125] might restore protein translation by inducing the ribosome to bypass a PTC, a process known as 'read through', provides a promising perspective. In fact, aminoglycoside antibiotics, PTC124 and RTC13 have been shown to partially restore dystrophin protein in the skeletal muscles of the transgenic mouse model for Duchenne muscular dystrophy [123, 124, 126]. In addition, both aminoglycoside antibiotics and PTC124 were able to suppress the PTC effects in the cystic fibrosis transmembrane conductance (CFTR) gene and to improve CFTR activity in cystic fibrosis patients [127]. Importantly, more than $90 \%$ of patients with McArdle disease have mutations in the PYGM gene that produce a PTC, including the most common p.R50X variation [121]. However, a preliminary trial with short-term (10 days) gentamicin treatment in McArdle disease patients presenting a PTC with 'read through' failed to normalize ${ }^{31} \mathrm{P}-\mathrm{MRS}$ indicators of myophosphorylase deficiency in muscle [128].

\subsubsection{Induced Expression of Brain and Liver Isoforms of Glycogen Phosphorylase in the Muscle}

The brain and liver isoforms of glycogen phosphorylase are only expressed in muscle tissue in the uterus, in neonates, and in regenerating mature fibers (i.e. after rhabdomyolysis episodes), but not in adult non-regenerating mature fibers, where only the muscle isoform, myophosphorylase, is expressed. Thus, any pharmacologic treatment able to upregulate the expression of the brain or liver isoforms of glycogen phosphorylase in the skeletal muscle of McArdle disease patients (e.g. valproate, an inhibitor of histone deacetylation) could theoretically alleviate the symptoms of the disease by partially restoring muscle glycogen breakdown. In fact, myophosphorylase-positive fibers have been identified in five of seven sheep with McArdle disease that were treated with this drug [129]. Additionally, it has been recently published that the injection or layering of notexin (a myotoxic phospholipase) in the muscles of the ovine McArdle model resulted in necrosis followed by regeneration of muscle fibers with the expression of both liver and brain isoforms of glycogen phosphorylase, leading to reduced muscle glycogen accumulation as well as increased strength of contraction and decreased fatigability of muscle fibers [109].

\subsubsection{Gene Therapy}

Gene therapy has also been evaluated in the McArdle ovine model using an adenovirus 5 vector and an adeno-associated virus serotype 2 containing myophosphorylase expression cassettes [130]. Intramuscular application of both vectors produced only local expression of functional myophosphorylase, i.e. limited to the surroundings of the injection site. Furthermore, the number of myophosphorylase-expressing fibers diminished with time, probably owing to an immune response, and expression of the non-muscle isoforms of glycogen phosphorylase was also observed in regenerating muscle fibers as a consequence of the muscular damage caused by the injection itself.

A major obstacle limiting gene therapy for muscle diseases comes from the fact that systemic gene transfer to striated muscles is hampered by the vascular endothelium, which represents a barrier to distribution of vectors through the bloodstream. With regard to this, a promising recent finding is that a single intravenous administration of recombinant adeno-associated virus pseudo-type 6 vectors with the inclusion of vascular endothelium growth factor/ vascular permeability enabled widespread muscle-specific expression of a functional micro-dystrophin protein in the skeletal muscles of a dystrophin-deficient mouse model of Duchenne dystrophy [131]. Future trials might be performed in McArdle disease patients.

\subsection{Nutritional Interventions Aimed at Maintaining High Blood Glucose Availability to Working Muscles}

A beneficial intervention for alleviating exercise intolerance symptoms and 'protecting' the muscle from rhabdomyolysis risk consists of ensuring that sufficient blood glucose (derived from high hepatic glycogen stores) is constantly made available to patients' muscles during the daytime. This can be effectively achieved by adopting a diet with a high proportion (65\%) of complex carbohydrates (such as those found in vegetables, fruits, cereals, 
bread, pasta and rice) and a low proportion (20\%) of fat [132]. Another strategy is the ingestion of simple carbohydrates before engaging in strenuous exercise: (i) in adults, $75 \mathrm{~g}$ of sucrose $30-40 \mathrm{~min}$ pre-exercise [14], or lower doses (30-40 g of glucose, fructose or sucrose, which translates to $400-500 \mathrm{~mL}$ of most commercially available sport drinks) closer to the start of exertion ( $\sim 5 \mathrm{~min}$ ) [133]; and (ii) in children, $20 \mathrm{~g}$ during the warm-up period preceding any vigorous exercise bout (for instance, physical education classes) [134]. Pre-exercise ingestion of simple carbohydrates is effective only during the time when patients are highly susceptible to muscle injury [14], i.e. during the first minutes of exercise, when there is low availability of circulating fuels and absence of glycogen-derived pyruvate, both of which dramatically impair the capacity for oxidative phosphorylation [9]. Thus, this treatment abolishes the spontaneous secondwind phenomenon (as mentioned in Sect. 2.2) [9, 14]. Preexercise carbohydrate ingestion also decreases perceived exertion on the Borg scale as well as heart rate, which is directly attributable to an increase in the oxidative capacity of the muscles [20]. On the other hand, although ingestion of high amounts of sucrose (75 g) causes sucrose-induced hyperinsulinemia (which has a negative effect on the mobilization and utilization of fatty acids), it seems that the oxidative benefit of enhanced glucose availability at the start of exercise mitigates any potential oxidative limitation attributable to decreased fatty acid mobilization [14].

\subsection{Exercise is Medicine!}

\subsubsection{The Paradoxical Concept of 'Healthy Patients'}

Individual differences in patients' physical activity levels largely explain the heterogeneity in disease severity mentioned in Sect. 1. Physically active patients, including children [135], are much more likely to improve their clinical course, i.e. move to the lowest severity group of patients (who are virtually asymptomatic and show no functional limitation in any daily life activity) over a 4-year period compared with their inactive peers (odds ratio 225; $95 \%$ confidence interval 20.3-2,496.7) [2]. In fact, some physically active patients have a peak oxygen uptake level $\left(V \mathrm{O}_{2 \text { peak }}\right) \geq 8$ metabolic equivalents (METs) [the minimum threshold for optimal health], with one Spanish patient reaching $\sim 11$ METs despite having, like all McArdle disease patients, no myophosphorylase activity in his muscle [2]. Importantly, the $V \mathrm{O}_{2 \text { peak }}$ values of these physically active patients are higher than those recently reported ( $\sim 7$ METs) in two 'atypical' patients described in the literature in whom there was a 'mild' or 'variant' form of McArdle disease, owing to some residual myophosphorylase activity (caused by the presence of an intronic splice mutation in one of the two PYGM alleles) [136]. (Of note, permanent restoration of myophosphorylase activity, even at below normal levels, would be an ideal outcome of eventual gene therapy, as previously mentioned).

McArdle disease patients with appropriate exercise habits can be almost as aerobically fit as unaffected people. After gradual, supervised training, a 38-year-old patient (with no myophosphorylase activity) could run regularly and cover $10 \mathrm{~km}$ in $\sim 60 \mathrm{~min}$ with no rhabdomyolysis [137]. The average time for recreational runners to complete a $10 \mathrm{~km}$ race generally falls between $75-80 \mathrm{~min}$.

\subsubsection{Exercise Interventions}

Although evidence from randomized controlled studies is still missing, there is data from interventional research showing that patients with McArdle disease, like the vast majority of humans, adapt favorably to regular exercise, i.e. with a significant increase in $V_{2} \mathrm{O}_{2 \text { peak }}$ after supervised aerobic exercise [64, 138]. Haller et al. showed a $36 \%$ increase in the cycle-ergometer peak work capacity of eight patients after a 14-week training program (four sessions/ week, duration 30-40 min, of cycling exercise at 60-70\% of peak heart rate), which was also accompanied by improvements in peak cardiac output (15\%), and citrate synthase $(80 \%)$ and $\beta$-hydroxyacyl coenzyme A dehydrogenase muscle enzyme levels (62\%) [138]. MateMunoz et al. reported a $44 \%$ increase in the $V O_{2 \text { peak }}$ of nine patients with an 8-month program (five weekly sessions, duration $\leq 60 \mathrm{~min}$, of walking/cycling exercise at $60 \%$ of peak heart rate) [64]. No dietary intervention was included in the study by Haller et al., whereas in the report by Mate-Munoz et al. patients ingested a commercialized sports drink during warm-up before each training session [equivalent to $\sim 30 \mathrm{~g}$ of simple carbohydrates (glucose and fructose)]. Pre-exercise carbohydrate ingestion might not be strictly necessary, at least in those patients who are more habituated to exercise, although in our experience it decreases their 'fear of exercise' by minimizing the risk of 'muscle crises' and attenuating the feelings of early fatigue and discomfort during the first minutes of a training session.

On the other hand, we believe pre-exercise carbohydrate is recommendable before light- to moderate-intensity weight-training exercise to prevent excessive muscle damage. Preliminary data from our group showed that a 15-year-old child with McArdle disease improved his one repetition maximum $(1 \mathrm{RM})$ bench press $(\sim 27 \%)$ and multipower squat performance $(\sim 6 \%)$ after a 6 -week, supervised, light- to moderate-intensity ( $\sim 65-70 \%$ of 1RM) weight lifting training program (two sessions/week) while suffering no myoglobinuria episode during testing or training sessions [139]. Furthermore, the patient changed to 
a lower disease severity class after training, i.e. he became virtually asymptomatic in terms of exercise limitations. However, more data are needed (and are in fact being currently generated by our group) in adult patients.

\subsubsection{Precautions}

Adaptation to exercise training should be a very gradual process, especially in those patients belonging to the highest severity class, i.e. reporting recurrent exerciseinduced myoglobinuria episodes. In general, vigorous dynamic ('aerobic') exercise (i.e. at a level that does not permit normal talking) should only be performed by the more habituated patients, while very intense exercises, particularly those involving high loads on low muscle mass (e.g. static muscle contractions such as handgrip exercise, heavy weightlifting), should be generally discouraged [8].

\section{Conclusion}

McArdle disease provides an interesting model of study in sports medicine, allowing insight to be gained into the understanding of glycogen-dependent muscle functions and exercise fatigue. Although patients have been traditionally advised to refrain from exercise, exercise prescription carefully supervised by professionals is a promising option for these patients, especially when considering that no effective enzyme replacement therapy is expected to be available in the foreseeable future. The fact that myophosphorylase deficiency might potentially affect brain or cardiac tissue provides further support to implement exercise interventions owing to the multiorgan benefits of this therapy (including improved neurogenesis and cognitive function) that no single drug is likely to outmatch [80]. Although patients' recruitment might pose difficulties owing to the low prevalence of the disease, future intervention research using, preferably, a randomized controlled trial design is needed to accumulate evidence on the best possible exercise training strategy for these patients.

Acknowledgments No sources of funding were used to assist in the preparation of this review. Alfredo Santalla, Gisela Nogales-Gadea, Niels Ørtenblad, Astrid Brull, Noemi de Luna, Tomàs Pinós and Alejandro Lucia have no potential conflicts of interest that are directly relevant to the content of this review. The authors original research in the field is supported by grants from the Spanish Ministry of Economy and Competitiveness [Fondo de Investigaciones Sanitarias (FIS), grants number PI12/00914 and PI13/00855]. Gisela Nogales-Gadea and Noemi de Luna are supported by Sara Borrell contracts of ISCIII CD10/00027 and CD11/00060, respectively. Astrid Brull is supported by an FIS grant of ISCIII FI11/00709.

\section{References}

1. McArdle B. Myopathy due to a defect in muscle glycogen breakdown. Clin Sci. 1951;10:20.

2. Lucia A, Ruiz JR, Santalla A, et al. Genotypic and phenotypic features of McArdle disease: insights from the Spanish national registry. J Neurol Neurosurg Psychiatry. 2012;83(3):322-8.

3. Bruno C, Cassandrini D, Martinuzzi A, et al. McArdle disease: the mutation spectrum of PYGM in a large Italian cohort. Hum Mut. 2006;27(7):718.

4. Quinlivan R, Buckley J, James M, et al. McArdle disease: a clinical review. J Neurol Neurosurg Psychiatry. 2010;81(11):1182-8.

5. Dubowith VSC, Oldfors A. Muscle biopsy; practical approach. 4th ed. New York: Elsevier; 2013.

6. Di Mauro S. Muscle glycogenoses: an overview. Acta Myol. 2007;26(1):35-41.

7. Lucia A, Nogales-Gadea G, Perez M, et al. McArdle disease: what do neurologists need to know? Nat Clin Pract Neurol. 2008;4(10):568-77.

8. Lucia AQR, Wakelin A, Martín MA, et al. The 'McArdle paradox': exercise is a good advice for the exercise intolerant. $\mathrm{Br} \mathrm{J}$ Sports Med. 2013;47(12):2.

9. Haller RG, Vissing J. Spontaneous, "second wind" and glucoseinduced second "second wind" in McArdle disease: oxidative mechanisms. Arch Neurol. 2002;59(9):1395-402.

10. Martin MA, Rubio JC, Buchbinder J, et al. Molecular heterogeneity of myophosphorylase deficiency (McArdle's disease): a genotype-phenotype correlation study. Ann Neurol. 2001;50(5):574-81.

11. Di Mauro SHA, Tsujino S. Nonlysosomal glycogenoses. In: Engel AGFAC, editor. Myology. New York: McGraw-Hill; 2004. p. $1535-58$.

12. Vissing J, Haller RG. A diagnostic cycle test for McArdle's disease. Ann Neurol. 2003;54(4):539-42.

13. Braakhekke JP, de Bruin MI, Stegeman DF, et al. The second wind phenomenon in McArdle's disease. Brain. 1986;109(Pt 6):1087-101.

14. Vissing J, Haller RG. The effect of oral sucrose on exercise tolerance in patients with McArdle's disease. $\mathrm{N}$ Engl $\mathrm{J}$ Med. 2003;349(26):2503-9.

15. Nadaj-Pakleza AA, Vincitorio CM, Laforet P, et al. Permanent muscle weakness in McArdle disease. Muscle Nerve. 2009;40(3):350-7.

16. Wolfe GI, Baker NS, Haller RG, et al. McArdle's disease presenting with asymmetric, late-onset arm weakness. Muscle Nerve. 2000;23(4):641-5.

17. Hultman E. Physiological role of muscle glycogen in man, with special reference to exercise. Circ Res. 1967;10:199-114.

18. Hargreaves M. Skeletal muscle metabolism during exercise in humans. Clin Exp Pharmacol Physiol. 2000;27(3):225-8.

19. Pernow B, Saltin B. Availability of substrates and capacity for prolonged heavy exercise in man. J Appl Physiol. 1971;31(3):416-22.

20. Bergstrom J, Hermansen L, Hultman E, et al. Diet, muscle glycogen and physical performance. Acta Physiol Scand. 1967;71(2):140-50.

21. Hermansen L, Hultman E, Saltin B. Muscle glycogen during prolonged severe exercise. Acta Physiol Scand. 1967;71(2):129-39.

22. Hargreaves M, McConell G, Proietto J. Influence of muscle glycogen on glycogenolysis and glucose uptake during exercise in humans. J Appl Physiol. 1995;78(1):288-92. 
23. Bangsbo J, Graham TE, Kiens B, et al. Elevated muscle glycogen and anaerobic energy production during exhaustive exercise in man. J Physiol. 1992;451:205-27.

24. Gollnick PD, Piehl K, Saubert CWT, et al. Diet, exercise, and glycogen changes in human muscle fibers. J Appl Physiol. 1972;33(4):421-5.

25. Chin ER, Allen DG. Effects of reduced muscle glycogen concentration on force, $\mathrm{Ca}^{2+}$ release and contractile protein function in intact mouse skeletal muscle. J Physiol. 1997;498(Pt 1):17-29.

26. Duhamel TA, Perco JG, Green HJ. Manipulation of dietary carbohydrates after prolonged effort modifies muscle sarcoplasmic reticulum responses in exercising males. Am J Physiol Regul Integr Comp Physiol. 2006;291(4):R1100-10.

27. Ortenblad N, Nielsen J, Saltin B, et al. Role of glycogen availability in sarcoplasmic reticulum $\mathrm{Ca}^{2+}$ kinetics in human skeletal muscle. J Physiol. 2011;589(Pt 3):711-25.

28. Ortenblad N, Westerblad H, Nielsen J. Muscle glycogen stores and fatigue. J Physiol. 2013;591(18):4405-13.

29. Dutka TL, Lamb GD. $\mathrm{Na}^{+}-\mathrm{K}^{+}$pumps in the transverse tubular system of skeletal muscle fibers preferentially use ATP from glycolysis. Am J Physiol Cell Physiol. 2007;293(3):C967-77.

30. James JH, Wagner KR, King JK, et al. Stimulation of both aerobic glycolysis and $\mathrm{Na}^{(+)}-\mathrm{K}^{(+)}$-ATPase activity in skeletal muscle by epinephrine or amylin. Am J Physiol. 1999;277(1 Pt 1):E176-86.

31. Friden J, Seger J, Ekblom B. Topographical localization of muscle glycogen: an ultrahistochemical study in the human vastus lateralis. Acta Physiol Scand. 1989;135(3):381-91.

32. Marchand I, Chorneyko K, Tarnopolsky M, et al. Quantification of subcellular glycogen in resting human muscle: granule size, number, and location. J Appl Physiol. 2002;93(5):1598-607.

33. Wanson JC, Drochmans P. Rabbit skeletal muscle glycogen. A morphological and biochemical study of glycogen beta-particles isolated by the precipitation-centrifugation method. J Cell Biol. 1968;38(1):130-50.

34. Nielsen J, Suetta C, Hvid LG, et al. Subcellular localizationdependent decrements in skeletal muscle glycogen and mitochondria content following short-term disuse in young and old men. Am J Physiol Endocrinol Metab. 2010;299(6):E1053-60.

35. Graham TE, Yuan Z, Hill AK, et al. The regulation of muscle glycogen: the granule and its proteins. Acta Physiol. 2010;199(4):489-98.

36. Wanson JC, Drochmans P. Role of the sarcoplasmic reticulum in glycogen metabolism. Binding of phosphorylase, phosphorylase kinase, and primer complexes to the sarcovesicles of rabbit skeletal muscle. J Cell Biol. 1972;54(2):206-24.

37. Nielsen J, Ortenblad N. Physiological aspects of the subcellular localization of glycogen in skeletal muscle. Appl Physiol Nutr Metab. 2013;38(2):91-9.

38. Nielsen JCA, Ortenblad N, Westerblad H. Subcellular distribution of glycogen and decreased tetanic $\mathrm{Ca}^{2+}$ in fatigued single intact mouse muscle fibres. J Physiol. 2014;592(9):2003-12.

39. Nielsen J, Schroder HD, Rix CG, et al. Distinct effects of subcellular glycogen localization on tetanic relaxation time and endurance in mechanically skinned rat skeletal muscle fibres. J Physiol. 2009;587(Pt 14):3679-90.

40. Entman ML, Keslensky SS, Chu A, et al. The sarcoplasmic reticulum-glycogenolytic complex in mammalian fast twitch skeletal muscle. Proposed in vitro counterpart of the contractionactivated glycogenolytic pool. J Biol Chem. 1980;255(13):6245-52.

41. Xu KY, Becker LC. Ultrastructural localization of glycolytic enzymes on sarcoplasmic reticulum vesticles. J Histochem Cytochem. 1998;46(4):419-27.
42. Hirata Y, Atsumi M, Ohizumi Y, et al. Mastoparan binds to glycogen phosphorylase to regulate sarcoplasmic reticular $\mathrm{Ca}^{2+}$ release in skeletal muscle. Biochem J. 2003;371(Pt 1):81-8.

43. Krishnamoorthy N, Santosh V, Yasha TC, et al. Glycogen storage disease type V (Mc Ardle's disease): a report on three cases. Neurol India. 2011;59(6):884-6.

44. Tachi N, Sasaki K, Tachi M, et al. Histochemical and biochemical studies in a patient with myophosphorylase deficiency. Eur Neurol. 1990;30(1):52-5.

45. De Stefano N, Argov Z, Matthews PM, et al. Impairment of muscle mitochondrial oxidative metabolism in McArdles's disease. Muscle Nerve. 1996;19(6):764-9.

46. Haller RG, Clausen T, Vissing J. Reduced levels of skeletal muscle $\mathrm{Na}^{+} \mathrm{K}^{+}$-ATPase in McArdle disease. Neurology. 1998;50(1):37-40.

47. Lewis SF, Haller RG. The pathophysiology of McArdle's disease: clues to regulation in exercise and fatigue. J Appl Physiol. 1986;61(2):391-401.

48. Zange J, Grehl T, Disselhorst-Klug C, et al. Breakdown of adenine nucleotide pool in fatiguing skeletal muscle in McArdle's disease: a noninvasive 31P-MRS and EMG study. Muscle Nerve. 2003;27(6):728-36.

49. Haller RG, Lewis SF, Cook JD, et al. Hyperkinetic circulation during exercise in neuromuscular disease. Neurology. 1983;33(10):1283-7.

50. Vissing J, Vissing SF, MacLean DA, et al. Sympathetic activation in exercise is not dependent on muscle acidosis. Direct evidence from studies in metabolic myopathies. J Clin Invest. 1998;101:1654-60.

51. Rae DE, Noakes TD, San Juan AF, et al. Excessive skeletal muscle recruitment during strenuous exercise in McArdle patients. Eur J Appl Physiol. 2010;110(5):1047-55.

52. Allen DG, Lamb GD, Westerblad H. Skeletal muscle fatigue: cellular mechanisms. Physiol Rev. 2008;88(1):287-332.

53. Dirksen RT. Sarcoplasmic reticulum-mitochondrial throughspace coupling in skeletal muscle. Appl Physiol Nutr Metab. 2009;34(3):389-95.

54. Nogales-Gadea G, Consuegra-Garcia I, Rubio JC, et al. A transcriptomic approach to search for novel phenotypic regulators in McArdle disease. PLoS One. 2012;7(2):e31718.

55. Odermatt A, Taschner PE, Khanna VK, et al. Mutations in the gene-encoding SERCA1, the fast-twitch skeletal muscle sarcoplasmic reticulum $\mathrm{Ca}^{2+}$ ATPase, are associated with Brody disease. Nat Genet. 1996;14(2):191-4.

56. Odermatt A, Barton K, Khanna VK, et al. The mutation of Pro789 to Leu reduces the activity of the fast-twitch skeletal muscle sarco(endo)plasmic reticulum $\mathrm{Ca}^{2+}$ ATPase (SERCA1) and is associated with Brody disease. Hum Genet. 2000;106(5):482-91.

57. Pan Y, Zvaritch E, Tupling AR, et al. Targeted disruption of the ATP2A1 gene encoding the sarco(endo)plasmic reticulum $\mathrm{Ca}^{2+}$ ATPase isoform 1 (SERCA1) impairs diaphragm function and is lethal in neonatal mice. J Biol Chem. 2003;278(15):13367-75.

58. Periasamy M, Kalyanasundaram A. SERCA pump isoforms: their role in calcium transport and disease. Muscle Nerve. 2007;35(4):430-42.

59. Cairns SP. Lactic acid and exercise performance: culprit or friend? Sports Med. 2006;36(4):279-91.

60. Vissing J, Haller RG. Mechanisms of exertional fatigue in muscle glycogenoses. Neuromuscul Disord. 2012;22(Suppl 3):S168-71.

61. Overgaard K, Nielsen OB. Activity-induced recovery of excitability in $\mathrm{K}^{(+)}$-depressed rat soleus muscle. Am J Physiol Regul Integr Comp Physiol. 2001;280(1):R48-55. 
62. Nielsen OB, de Paoli F, Overgaard K. Protective effects of lactic acid on force production in rat skeletal muscle. J Physiol. 2001;536(Pt 1):161-6.

63. O'Dochartaigh CS, Ong HY, Lovell SM, et al. Oxygen consumption is increased relative to work rate in patients with McArdle's disease. Eur J Clin Invest. 2004;34(11):731-7.

64. Mate-Munoz JL, Moran M, Perez M, et al. Favorable responses to acute and chronic exercise in McArdle patients. Clin J Sports Med. 2007;17(4):297-303.

65. Chavarren J, Calbet JA. Cycling efficiency and pedalling frequency in road cyclists. Eur J Appl Physiol Occup Physiol. 1999;80(6):555-63.

66. Brooks GA, Butterfield GE, Wolfe RR, et al. Increased dependence on blood glucose after acclimatization to 4,300 m. J Appl Physiol. 1991;70(2):919-27.

67. Keel BR, Brit M. McArdle's disease: a clinical review and case report. Tenn Med. 2013;106(10):33, 37.

68. Miteff F, Potter HC, Allen J, et al. Clinical and laboratory features of patients with myophosphorylase deficiency (McArdle disease). J Clin Neurosci. 2011;18(8):1055-8.

69. Pillarisetti J, Ahmed A. McArdle disease presenting as acute renal failure. South Med J. 2007;100(3):313-6.

70. Getachew E, Prayson RA. Pathologic quiz case: a man with exertion-induced cramps and myoglobinuria. McArdle disease (glycogenosis type $\mathrm{V}$ or myophosphorylase deficiency). Arch Pathol Lab Med. 2003;127(9):1227-8.

71. Leite AON, Rocha M. McArdle diesease: a case report and review. Int Med Case Rep J. 2012;20(5):1-4. doi:10.2147/ IMCRJ.S28664.

72. Mineo I, Kono N, Shimizu T, et al. Excess purine degradation in exercising muscles of patients with glycogen storage disease types V and VII. J Clin Invest. 1985;76(2):556-60.

73. Brooke MH, Patterson VH, Kaiser KK. Hypoxanthine and Mcardle disease: a clue to metabolic stress in the working forearm. Muscle Nerve. 1983;6(3):204-6.

74. Kitaoka Y, Ogborn DI, Nilsson MI, et al. Oxidative stress and Nrf2 signaling in McArdle disease. Mol Genet Metab. 2013;110(3):297-302.

75. Russo PJ, Phillips JW, Seidler NW. The role of lipid peroxidation in McArdle's disease: applications for treatment of other myopathies. Med Hypotheses. 1992;39(2):147-51.

76. Tidball JG. Inflammatory cell response to acute muscle injury. Med Sci Sport Exerc. 1995;27(7):1022-32.

77. Pedersen BK, Ostrowski K, Rohde T, et al. The cytokine response to strenuous exercise. Can J Physiol Pharmacol. 1998;76(5):505-11.

78. Petersen AMW, Pedersen BK. The anti-inflammatory effect of exercise. J Appl Physiol. 2005;98(4):1154-62.

79. Bruunsgaard $\mathrm{H}$. Physical activity and modulation of systemic low-level inflammation. J Leukoc Biol. 2005;78(4):819-35.

80. Fiuza-Luces C, Garatachea N, Berger NA, et al. Exercise is the real polypill. Physiology. 2013;28(5):330-58.

81. Lucia A, Smith L, Naidoo M, et al. McArdle disease: another systemic low-inflammation disorder? Neurosci Lett. 2008;431(2):106-11.

82. Lawrence JC Jr, Roach PJ. New insights into the role and mechanism of glycogen synthase activation by insulin. Diabetes. 1997;46(4):541-7.

83. Nielsen JN, Vissing J, Wojtaszewski JFP, et al. Decreased insulin action in skeletal muscle from patients with McArdle's disease. Am J Physiol Endocrinol Metab. 2002;282(6):E1267-75.

84. Nielsen JN, Wojtaszewski JFP, Haller RG, et al. Role of 5'AMPactivated protein kinase in glycogen synthase activity and glucose utilization: insights from patients with McArdle's disease. J Physiol. 2002;541(Pt 3):979-89.
85. Nogales-Gadea G, Mormeneo E, Garcia-Consuegra I, et al. Expression of glycogen phosphorylase isoforms in cultured muscle from patients with McArdle's disease carrying the p.R771PfsX33 PYGM mutation. PLoS One. 2010;5(10):pii.e13164

86. Valdes S, Rojo-Martinez G, Soriguer F. Evolution of prevalence of type 2 diabetes in adult Spanish population. Med Clin. 2007;129(9):352-5.

87. Roach PJ, Cao Y, Corbett CA, et al. Glycogen metabolism and signal transduction in mammals and yeast. Adv Enzyme Regul. 1991;31:101-20.

88. Prats C, Helge JW, Nordby P, et al. Dual regulation of muscle glycogen synthase during exercise by activation and compartmentalization. J Biol Chem. 2009;284(23):15692-700.

89. Meyer F, Heilmeyer LM Jr, Haschke RH, et al. Control of phosphorylase activity in a muscle glycogen particle: I. Isolation and characterization of the protein-glycogen complex. J Biol Chem. 1970;245(24):6642-8.

90. Nielsen JN, Richter EA. Regulation of glycogen synthase in skeletal muscle during exercise. Acta Physiol Scand. 2003;178(4):309-19.

91. Zachwieja JJ, Costill DL, Pascoe DD, et al. Influence of muscle glycogen depletion on the rate of resynthesis. Med Sci Sport Exerc. 1991;23(1):44-8.

92. Aschenbach WG, Suzuki Y, Breeden K, et al. The musclespecific protein phosphatase PP1G/R(GL)(G(M))is essential for activation of glycogen synthase by exercise. J Biol Chem. 2001;276(43):39959-67.

93. Roelofs RI, Engel WK, Chauvin PB. Histochemical phosphorylase activity in regenerating muscle fibers from myophosphorylase-deficient patients. Science. 1972;177(4051):795-7.

94. Mitsumoto H. McArdle disease: phosphorylase activity in regenerating muscle fibers. Neurology. 1979;29(2):258-62.

95. Felice KJ, Grunnet ML, Sima AA. Selective atrophy of type 1 muscle fibers in McArdle's disease. Neurology. 1996;47(2):581-3.

96. Bresolin N, Miranda A, Jacobson M, et al. Phosphorylase isoenzymes of human brain. Neurochem Pathol. 1983;1:171-8.

97. Pfeiffer-Guglielmi B, Fleckenstein B, Jung G, et al. Immunocytochemical localization of glycogen phosphorylase isozymes in rat nervous tissues by using isozyme-specific antibodies. J Neurochem. 2003;85(1):73-81.

98. Schmid H, Pfeiffer-Guglielmi B, Dolderer B, et al. Expression of the brain and muscle isoforms of glycogen phosphorylase in rat heart. Neurochem Res. 2009;34(3):581-6.

99. Rommel O, Kley RA, Dekomien G, et al. Muscle pain in myophosphorylase deficiency (McArdle's disease): the role of gender, genotype, and pain-related coping. Pain. 2006;124(3):295-304.

100. Di Mauro S, Bresolin N. Phosphorylase deficiency. New York: McAGraw-Hill; 1986

101. Edelstyn NM, Quinlivan R. A pilot study of neuropsychological performance in McArdle disease. Neuromuscul Disord. 2007;17(9):860 [Poster: M.P4.04].

102. Mancuso M, Orsucci D, Volterrani D, et al. Cognitive impairment and McArdle disease: is there a link? Neuromuscul Disord. 2011;21(5):356-8.

103. Nicholls DP, Campbell NP, Stevenson HP, et al. Angina in McArdle's disease. Heart. 1996;76(4):372-3.

104. Ratinov G, Baker WP, Swaiman KF. Mcardle's syndrome with previously unreported electrocardiographic and serum enzyme abnormalities. Ann Intern Med. 1965;62:328-34.

105. Wheeler SD, Brooke MH. Vascular insufficiency in McArdle's disease. Neurology. 1983;33(2):249-50.

106. Moustafa SPD, Connelly MS. Unforeseen cardiac involvement in McArdle's patients. Heart Lung Circ. 2013;22:769-71. 
107. Angelos S, Valberg SJ, Smith BP, et al. Myophosphorylase deficiency associated with rhabdomyolysis and exercise intolerance in 6 related Charolais cattle. Muscle Nerve. 1995;18(7):736-40.

108. Tan P, Allen JG, Wilton SD, et al. A splice-site mutation causing ovine McArdle's disease. Neuromuscul Disord. 1997;7(5):336-42.

109. Howell JM, Walker KR, Creed KE, et al. Phosphorylase reexpression, increase in the force of contraction and decreased fatigue following notexin-induced muscle damage and regeneration in the ovine model of McArdle disease. Neuromuscul Disord. 2014;24(2):167-77.

110. Nogales-Gadea G, Pinos T, Lucia A, et al. Knock-in mice for the R50X mutation in the PYGM gene present with McArdle disease. Brain. 2012;135(Pt 7):2048-57.

111. MacLean D, Vissing J, Vissing SF, et al. Oral branched-chain amino acids do not improve exercise capacity in McArdle disease. Neurology. 1998;51(5):1456-9.

112. Day TJ, Mastaglia FL. Depot-glucagon in the treatment of McArdle's disease. Aust N Z J Med. 1985;15(6):748-50.

113. Poels PJ, Braakhekke JP, Joosten EM, et al. Dantrolene sodium does influence the second-wind phenomenon in McArdle's disease. Electrophysiological evidence during exercise in a double-blind placebo-controlled, cross-over study in 5 patients. J Neurol Sci. 1990;100(1-2):108-12.

114. Lane RJ, Turnbull DM, Welch JL, et al. A double-blind, placebo-controlled, crossover study of verapamil in exertional muscle pain. Muscle Nerve. 1986;9(7):635-41.

115. Phoenix J, Hopkins P, Bartram C, et al. Effect of vitamin B6 supplementation in McArdle's disease: a strategic case study. Neuromuscul Disord. 1998;8(3-4):210-2.

116. Sato S, Ohi T, Nishino I, et al. Confirmation of the efficacy of vitamin B6 supplementation for McArdle disease by follow-up muscle biopsy. Muscle Nerve. 2012;45(3):436-40.

117. Steele IC, Patterson VH, Nicholls DP. A double blind, placebo controlled, crossover trial of D-ribose in McArdle's disease. J Neurol Sci. 1996;136(1-2):174-7.

118. Vorgerd M, Grehl T, Jager M, et al. Creatine therapy in myophosphorylase deficiency (McArdle disease): a placebo-controlled crossover trial. Arch Neurol. 2000;57(7):956-63.

119. Vorgerd M, Zange J, Kley R, et al. Effect of high-dose creatine therapy on symptoms of exercise intolerance in McArdle disease: double-blind, placebo-controlled crossover study. Arch Neurol. 2002;59(1):97-101.

120. Frischmeyer PA, Dietz HC. Nonsense-mediated mRNA decay in health and disease. Hum Mol Genet. 1999;8(10):1893-900.

121. Nogales-Gadea G, Rubio JC, Fernandez-Cadenas I, et al. Expression of the muscle glycogen phosphorylase gene in patients with McArdle disease: the role of nonsense-mediated mRNA decay. Hum Mut. 2008;29(2):277-83.

122. Schroeder R, Waldsich C, Wank H. Modulation of RNA function by aminoglycoside antibiotics. EMBO J. 2000;19(1):1-9.

123. Welch EM, Barton ER, Zhuo J, et al. PTC124 targets genetic disorders caused by nonsense mutations. Nature. 2007;447(7140):87-91.
124. Kayali R, Ku J-M, Khitrov G, et al. Read-through compound 13 restores dystrophin expression and improves muscle function in the mdx mouse model for Duchenne muscular dystrophy. Hum Mol Genet. 2012;21(18):4007-20.

125. Gonzalez-Hilarion S, Beghyn T, Jia J, et al. Rescue of nonsense mutations by amlexanox in human cells. Orphanet J Rare Dis. 2012;7:58.

126. Barton-Davis ER, Cordier L, Shoturma DI, et al. Aminoglycoside antibiotics restore dystrophin function to skeletal muscles of mdx mice. J Clin Invest. 1999;104(4):375-81.

127. Bedwell DM, Kaenjak A, Benos DJ, et al. Suppression of a CFTR premature stop mutation in a bronchial epithelial cell line. Nat Med. 1997;3(11):1280-4.

128. Schroers A, Kley RA, Stachon A, et al. Gentamicin treatment in McArdle disease: failure to correct myophosphorylase deficiency. Neurology. 2006;66(2):285-6.

129. Howell JM, Quinlinan R, Sewry C. Investigation of possible treatment regimes for McArdle's disease using the sheep model of the disease. Neuromuscul Disord. 2008;18(9):828 [Poster: G.P.16.06].

130. Howell JM, Walker KR, Davies L, et al. Adenovirus and adenoassociated virus-mediated delivery of human myophosphorylase cDNA and LacZ cDNA to muscle in the ovine model of McArdle's disease: expression and re-expression of glycogen phosphorylase. Neuromuscul Disord. 2008;18(3):248-58.

131. Gregorevic P, Blankinship MJ, Allen JM, et al. Systemic delivery of genes to striated muscles using adeno-associated viral vectors. Nat Med. 2004;10(8):828-34.

132. Andersen ST, Vissing J. Carbohydrate- and protein-rich diets in McArdle disease: effects on exercise capacity [published erratum appears in J Neurol Neurosurg Psychiatry. 2010;81(12): 1414]. J Neurol Neurosurg Psychiatry. 2008;79(12):1359-63.

133. Andersen ST, Haller RG, Vissing J. Effect of oral sucrose shortly before exercise on work capacity in McArdle disease. Arch Neurol. 2008;65(6):786-9.

134. Perez M, Mate-Munoz JL, Foster C, et al. Exercise capacity in a child with McArdle disease. J Child Neurol. 2007;22(7):880-2.

135. Perez M, Foster C, Gonzalez-Freire M, et al. One-year follow-up in a child with McArdle disease: exercise is medicine. Pediatr Neurol. 2008;38(2):133-6.

136. Vissing J, Duno M, Schwartz M, et al. Splice mutations preserve myophosphorylase activity that ameliorates the phenotype in McArdle disease. Brain. 2009;132(Pt 6):1545-52.

137. Perez M, Moran M, Cardona C, et al. Can patients with McArdle's disease run? Br J Sports Med. 2007;41(1):53-4.

138. Haller RG, Wyrick $P$, Taivassalo $T$, et al. Aerobic conditioning: an effective therapy in McArdle's disease. Ann Neurol. 2006;59(6):922-8.

139. Garcia-Benitez S, Fleck SJ, Naclerio F, et al. Resistance (weight lifting) training in an adolescent with McArdle disease. J Child Neurol. 2013;28(6):805-8. 